\title{
Periscope
}

however, did not always parallel the objective improvement, since the patients usually felt better on the sedative treatment though the lowering of the blood pressure was more marked when they were taking potassium thiocyanate in large doses.

M. H. Finsberg (Journ. Amer. Med. Assoc., 1930, vol. xliv., p. I82).

D. M. D.

\section{UNUNITED FRACTURES OF THE CLAVICLE.}

Immobilization is so difficult and the practical results are so satisfactory that fractures of the clavicle receive but scant attention. Only extreme æstheticism stimulates the former, while in the latter non-union is ascribed to some unknown constitutional peculiarity and the onus lies with the patient. Pseudarthrosis in itself is of little consequence for no disability results when, congenitally, a joint occurs in the middle of the clavicular body, but a false joint from fracture seems to be more often associated with pressure symptoms on adjacent parts.

A female, aged 50 years, fell on her left shoulder sustaining a fracture of the clavicle at the junction of the lateral with the middle third of the bone. There was no union three months later and the medial fragment, overriding the lateral fragment, pressed under the skin threatening necrosis and ulceration. That there were also signs of blood-vascular compression appeared from cyanosis of the hand with formication in the first to fourth fingers, the thumb being specially involved. The grasp of the affected hand was diminished in power. Operation showed an oblique fracture with a regular "washer" of fibrous tissue interposed. Removal of all fibrous interpositions and the accurate approximation of the fragments by three ligatures produced an excellent result and immediate disappearance of all untoward symptoms.

A male, aged 36 years, suffered a comminuted fracture of the left clavicle as part of his injuries in an automobile accident. Five months later the fracture appeared healed with much displacement and a great amount of callus. He had pain and want of power in the upper limb, atrophy of muscles and paresis of the hand. His symptoms were aggravated by a persistent cough of pulmonary origin, probably tuberculous. At operation union between the fragments was found imperfect and a portion of the comminuted bone projected posteriorly to the brachial plexus. Fixation of the fragments was affected by a plate and four screw-nails which were removed under a local anæsthetic three months later.

A. Chalier, "Fractures de la clavicule avec pseudarthrose et avec troubles de compression" (Lyon Chirurg., s930, xxvii., 638).

D. M. G. 